\title{
DEVELOPING DIGITAL LITERACIES THROUGH CONTINUING PROFESSIONAL DEVELOPMENT
}

\author{
Dr. Gráinne CONOLE, Ph.D., \\ Visiting professor, Dublin City University, UK \\ gconole@gmail.com
}

\begin{abstract}
Digital technologies have much to offer education and to enable learners to interact with rich multimedia, and to communicate and collaborate. This paper argues that to harness the potential of digital technologies for learning new digital literacies skills are needed. To support teachers in the development of these literacies new and innovative forms of Continuing Professional Development are needed. The paper concludes with a description of the 7Cs of Learning Design framework, which aims to help teachers make more pedagogically informed design decisions that make appropriate use of digital technologies.
\end{abstract}

Keywords: Continuing Professional Development; Digital Literacies; Digital Technologies; Learning Design;

\section{Introduction}

This paper focuses on innovative models and practices of Continuous Professional Development (CPD) in order to improve the effectiveness of teaching and learning in higher education. The premise is that effective and innovative CPD has the potential to improve academics' capacity to use new pedagogical models (HoTEL, n.d.) for teaching, at the same time as enhancing outcomes for learners. It describes the 7Cs of Learning Design framework, which aims to help teachers make pedagogically informed design decision that make appropriate use of digital technologies.

\section{Digital technologies}

Technology affects every aspect of our everyday lives and has changed the way we learn, communicate, locate information and acquire knowledge (Kelentríc et al., 2017). Digital technologies have significant promise in terms of facilitating innovative learning and teaching. They offer a rich 
variety of ways in which learners can interact with multimedia content and communicate and collaborate. Social media mean that learners are now part of a global community of peers and mobile devices mean that learning any where, anytime is now a reality. The rise of Massive Open Online Courses (MOOCs) are challenging existing educational offerings and new forms of recognition of learning are arising; such as certificates of participation, digital badges and application of blockchain technologies (Witthaus et al., 2016; Grech and Camilleri, 2017, OUA, 2018). New digital technologies are arising all the time, such as augmented reality and artificial intelligence and these clearly have significant implications for learning and teaching.

Digital technologies provide opportunities for great flexibility, interactivity, and accessibility for engaging teaching and learning at individual, group and societal levels (Lawrence and Tar, 2018). The NMC Horizon and the UK OU's Innovating Pedagogy reports provide an overview of key emergent digital technologies and consider the implications for practice (NMC Horizon report, 2017; Innovating Pedagogy, 2017). The key point is that innovative and impactful CPD has never been more important in order to help individuals and institutions respond to these developments and harness the educational potential of new digital technologies.

Technology-enhanced education offers a variety of opportunities for higher education institutions (HEIs), such as: widening the student body, engaging with non-traditional and remote learners, blending classroom and virtual higher education, cross-border cooperation between institutions, more adapted/tailor-made provision, and mainstreaming of a more interactive teaching and learning experiences (Eurydice, 2017; Haywood et al., 2015; Scott, 2015a, Scott, 2015b, Scott, 2015c). Despite these developments and opportunities, the majority of European HEIs have made little progress in adapting their course offerings accordingly. Learning Management Systems are now standard in most institutions, but are mainly used as content repositories and, despite the fact that many institutions are experimenting with using MOOCs this remains a peripheral innovation. Despite the promise of digital technologies, the reality of them transforming education has not been realised and most pedagogical practices remain fundamentally the same (Conole, 2013).

Furthermore, it is estimated that $65 \%$ of jobs in the future do not even exist today (World Economic Forum, 2016), therefore we need to shift from knowledge recall to helping learners develop digital competences and enable them to be lifelong learners (OUA, 2018). Learners need to shift from being passive consumers to critical users and active producers of knowledge (Kelentríc et al., 2017). The shift towards a more student-centred approach in teaching and learning within higher education is rapidly materializing across Europe. Recent technological developments can be instrumental in 
supporting this movement. The growing numbers of students constitute a challenge when it comes to ensuring the quality and relevance of higher education. At the same time new providers are entering the market (Haywood, et al., 2015).

Teachers play a crucial role in teaching and learning but face the challenge of keeping abreast of the rapidly growing knowledge base in education (Merchie et al., 2018). Indeed, the role of educators is crucial in supporting the integration of digital technologies (Conrads et al., 2017). Education systems need to provide learners with adequate competencies to cope with social and professional realities. However, traditional educational systems are not best equipped to cope with the changing nature of learning, the changing demands of learners and their competencies and the need for new ways of teaching and managing complexities. The 'renewed agenda for higher education' report argues that having good university teachers is crucial for Higher Education (HE):

Too many higher education teachers have received little or no pedagogical training and systematic investment in teachers' continuous professional development remains the exception. National and institutional strategies to improve career opportunities and rewards for good teachers are becoming more common but are far from standard (EAC, 2017, p.5)

\section{Digital literacies}

As a result of the potential impact of digital technologies on education, new digital literacies are needed by teachers to make effective use of them for learning.

Open Educational Resources (OER) and Massive Open Online Courses (MOOCs) offer fantastic opportunities for opening up education and to potentially supporting social inclusion and widening participation. UNSECO argue that education is a fundamental human right and therefore should be freely available. Despite the rhetoric and the hype around OER and MOOCs in reality OER are not being used extensively by students or teachers and MOOCs are predominantly taken by those who are already educated. New digital literacies are needed to harness the potential of OER and MOOCs (Jenkins et al., 2006). ${ }^{1}$ OER and MOOCs are examples of disruptive innovations as they are challenging existing educational provision, which is good, in that institutions need to think hard about and make clear what a student will get by attending that institution, and what their will their student

\footnotetext{
${ }^{1}$ See also the JISC digital literacies resources: https://www.jisc.ac.uk/guides/developingdigital-literacies
} 
experience will be. Jenkins et al. (2006) argue that learners need new forms of digital literacies to be part of what they refer to as today's participatory culture. They argue that a participatory culture is a culture with relatively low barriers to artistic expression and civic engagement, strong support for creating and sharing one's creations, and some type of informal mentorship whereby what is known by the most experienced is passed along to novices. A participatory culture is also one in which members believe their contributions matter, and feel some degree of social connection with one another (at the least they care what other people think about what they have created).

Forms of participatory culture include:

- Affiliations - memberships, formal and informal, in online communities centred around various forms of media, such as Friendster, Facebook, message boards, meta-gaming, game clans, or MySpace).

- Expressions - producing new creative forms, such as digital sampling, fan video-making, fan fiction writing, mash-ups, etc.).

- Collaborative Problem-solving - working together in teams, formal and informal, to complete tasks and develop new knowledge (such as through Wikipedia, alternative reality gaming, spoiling).

- Circulations - Shaping the flow of media (such as podcasting, blogging).

They list the following as the new set of skills that learners need to develop:

- Play - the capacity to experiment with one's surroundings as a form of problem-solving

- Performance - the ability to adopt alternative identities for the purpose of improvisation and discovery

- Simulation - the ability to interpret and construct dynamic models of realworld processes

- Appropriation - the ability to meaningfully sample and remix media content

- Multitasking - the ability to scan one's environment and shift focus as needed to salient details.

- Distributed Cognition - the ability to interact meaningfully with tools that expand mental capacities Collective Intelligence - the ability to pool knowledge and compare notes with others toward a common goal Judgment - the ability to evaluate the reliability and credibility of different information sources

- Transmedia Navigation - the ability to follow the flow of stories and information across multiple modalities

- Networking — the ability to search for, synthesize, and disseminate information Negotiation - the ability to travel across diverse communities, 
discerning and respecting multiple perspectives, and grasping and following alternative norms.

- To this list I would add creativity.

As mentioned above a key challenge is that teachers and learners lack the necessary digital literacy skills to harness the potential of digital technologies. However, there is also inertia in existing educational structures and a hesitance to engage in new practices. For research-intensive institutions teaching is the poor sister, with research being privileged and rewarded. Furthermore, there is a lack of understanding and clarity of how to recognise learning through OER and MOOCs. Models are emerging, such as: digital badges, certificates of participation/completion, and recognition through organisations like the OERu, but these are still in their infancy. An IPTS commissioned report, OpenCred (Witthaus et al., 2016), looked at models for recognition of non-formal learning through MOOCs. Another barrier is around pedagogies. Firstly, most OER and MOOCs do not make the underlying pedagogy explicit. Secondly, it is not clear what pedagogies are most appropriate to support open learning. For OER work that I did with colleague found the following barriers to uptake: i) the pedagogies of OER were not clear, ii) the difficulty of repurposing, iii) the lack of clarity of perceived benefits, and iv) a culture of academics wanting the create their own resources.

Continuing Professional Development

New forms of Continuing Professional Development (CPD) are needed to enable teachers to adopt innovative practices and harness the potential of digital technologies. There is considerable literature on CPD and different perspectives on the nature of what works and why.

CPD can be defined as:

Formal courses and programmes in professional education and... the formal and informal development of professional skills that occur in the workplace, can refer to engagement with accredited modules or programmes, participating in workshops, presenting at a conference, or doing pedagogical research (National Forum for the Enhancement of Teaching and Learning in Higher Education, 2015).

\section{Darling-Hammond et al. (2017) define it as:}

Effective professional development is defined as structured professional learning that results in changes to teacher knowledge and practices, and improvements in student learning outcomes. Professional learning is conceptualised as a product of both externally provided and job- 
embedded activities that increase teachers' knowledge and help them change their instructional practice in ways that support student learning.

Innovative case studies of CPD focus on effective use of digital technologies and innovative practice more generally to support CPD, such as for instance through MOOCs (Laurillard, 2016). However, understanding CPD is complex, contested and culturally rooted. There is a crucial link between teachers' pedagogical beliefs and their educational use of technology (Tondeur et al., 2016), which must be taken into account if CPD is to be effective and impactful. Faculty professional development is essential to ensure good quality teaching and learning. There are a variety of types of professional development; from formal courses and masters programmes, through to workshops, peer observation, mentoring, peer networking, the development of portfolios of professional practice and learning and teaching conferences (Gast et al., 2017; Wenner and Campbell, 2017). One of the most valuable means is learning from colleagues by engaging in informal conversations (Thomson and Trigwell, 2016). Conversation can be used for a variety of purposes, to: help teachers manage their teaching context, improve their teaching and student learning, reassure themselves about their teaching practice, discuss teaching related issues and problems and transform their thinking and practice of teaching. Coupled to this team-based professional development is increasingly being recognized as important (Gast et al., 2017). Finally, the literature indicates the importance of providing a supportive environment for CPD and opportunities for teachers to act as active agents in an authentic process of development (Jääskelä et al., 2017). In addition, it is recognized that it is important to reward teaching excellence and help build a community of peers (van Lankveld et al., 2017). Quality initiatives such as teaching awards, development grants and the establishment of centres of teaching excellence can also make a significant difference. Staff development is believed to help increase individuals' confidence in teaching ability and provide them with opportunities to connect with like-minded peers to exchange ideas, and to enable them to develop an educational language.

\section{The 7Cs of Learning Design Framework}

When they design a learning intervention, teachers typically focus on content, drawing on their own experience of learning (usually through lectures and tutorials). The 7Cs framework shifts the focus away from content to activities and the ultimate learner experience. The underlying philosophy associated with the 7Cs framework is shifting from a beliefbased approach to design to one that is design-based. It is about helping the 
teacher/designer represent their designs, and fosters reflection and creativity. Visualising the design means that it can be shared and discussed with others.

Figure 1 illustrates the 7Cs of Learning Design framework. The first C, Conceptualise, is about creating a vision for the course or module being designed. It helps the teacher/designer think about the nature of the learners who are likely to take the course or module, their age range, diversity, characteristics, skills, perceptions and aspirations. It is also about articulating the core principles associated with the course or module. The next four Cs are concerned with designing the resources and activities that the learners will engage with. The Create $\mathrm{C}$ helps the teacher/designer articulate what learning materials need to be created, whether these are text-base, interactive materials, podcasts or videos. In addition, it covers the use or repurposing of Open Educational Resources. Finally, the teacher/designer might also create some activities, which require the learners to create their own content. The Communicate $\mathrm{C}$ is concerned with methods to facilitate communication, between the learner and the tutor, the learner and their peers, and the broader community through social media. This might range from effective mechanisms for fostering discussion in a forum, through effective moderation, or looser communication through social media. Similarly, the Collaborate $\mathrm{C}$ is about fostering mechanisms to enable collaboration or group work. Finally, the Consider $\mathrm{C}$, is concerned with ways in which reflection and demonstration of learning achievements can be promoted. Assessment might be diagnostic, formative or summative. The Combine $\mathrm{C}$ enables the teacher/designer to step back and reflect on the design process to date and look at the design from different perspectives. Finally, the Consolidate $\mathrm{C}$ is about implementing the design in a real-life context and evaluating its effectiveness. 


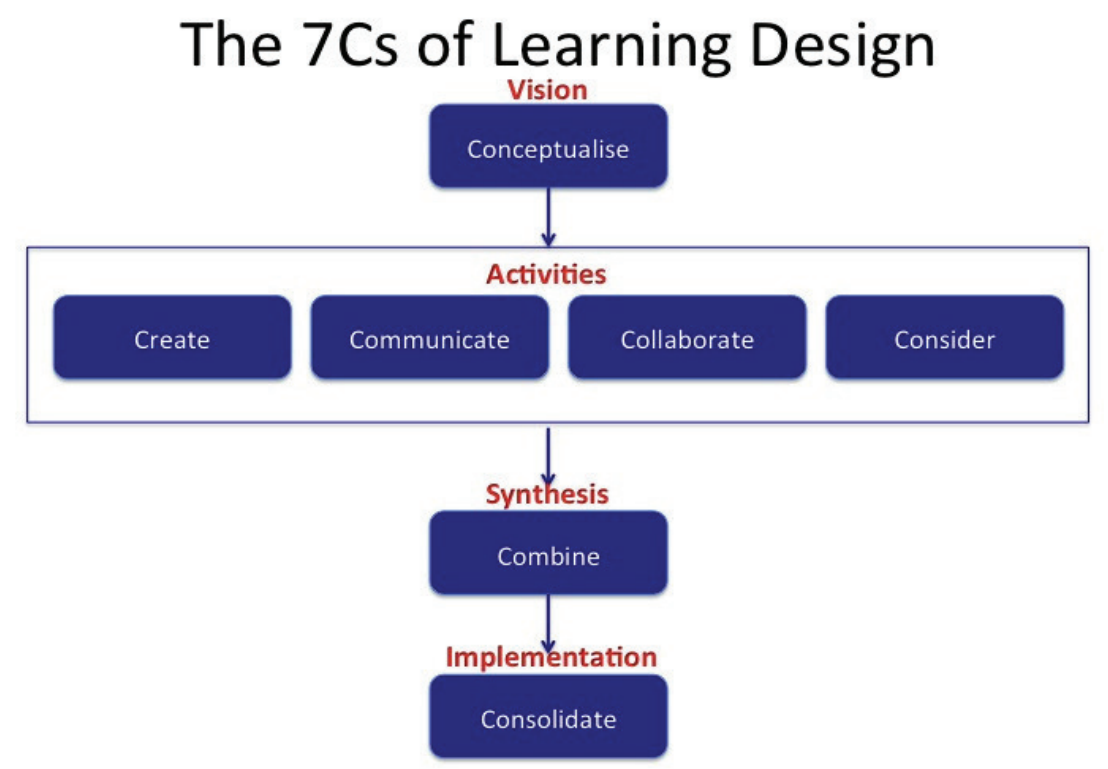

Figure 1: The 7Cs of Learning Design Framework

\section{Conclusion}

This paper has argued that new forms of CPD are needed to help teachers design innovative learning interventions to help learners be critical problem solving and to enable them to be lifelong learners.

\section{References}

Conole, G., (2013), Designing for learning in an open world, in M. Spector and S.P. Lejoie (Eds.), Explorations in the Learning Sciences, Instructional Systems and Performance Technologies, New York: Springer.

Conrads, J., Rasmussen, M., Winters, N., Geniert, A. and Langer, L., (2017), Digital education policies in Europe and beyond, JRC Science for policy report.

Darling-Hammond, L., Hyler, M.E. and Garnder, M. (2017), Effective teacher professional development, a learning policy institute report, available online at https://learningpolicyinstitute.org/product/effective-teacher-professionaldevelopment-report, last accessed 20st March 2018).

EAC (2017), Communication from the commission to the European parliament, the council, the European economic and social committee and the committee of the regions on a review EU agenda for Higher Education.

Eurydice (2017), Modernisation of Higher Education in Europe: academic staff - 2017, available online at 
https://webgate.ec.europa.eu/fpfis/mwikis/eurydice/index.php/Publications: Modernisation_of_Higher_Education_in_Europe:_Academic_Staff_\%E2\%8 0\%93_2017, last accessed $26^{\text {th }}$ March 2018.

Gast, I., Schildkamp, K. and van der Veen, J.T. (2017), Team-based professional development interventions in Higher Education: a systematic review, Review of educational research, Vo. 87, No. 4, 736-767.

Grech, A. and Camilleri, A. F. (2017) Blockchain in Education. Inamorato dos Santos, A. (ed.) EUR 28778 EN; doi:10.2760/60649 ), a JRC Science for policy report, available online at http://www.pedocs.de/volltexte/2018/15013/pdf/Grech_Camilleri_2017_Blo ckchain_in_Education.pdf, last accessed $20^{\text {th }}$ March 2018.

Haywood, J., Connelly, L., Henderikx, P., Weller, M. and Williams, K. (2015), The changing pedagogical landscape report.

HoTEL (n.d.), HoTEL learning theories map, available online at http://hotelproject.eu/sites/default/files/content-files/documentation/LearningTheory.pdf, last accessed 20 ${ }^{\text {th }}$ March 2018.

Innovating Pedagogy Report (2017), Milton Keynes: Open University, available online at http://www.open.ac.uk/blogs/innovating/ , last accessed $20^{\text {th }}$ March 2018

Jääskelä, P., Häkkinen, P. and Rasku-Puttonen, H. (2017): Supporting and constraining factors in the development of university teaching experienced by teachers, Teaching in Higher Education.

Jenkins, H., Clinton, K., Purushotma, P., Robison, A.J. and Weigel, M. (2016), Confronting the challenges of participatory culture: media education for the $21^{\text {st }}$ Century, available online at https://www.macfound.org/media/article_pdfs/JENKINS_WHITE_PAPER.P DF.

Kelentríc, M., Helland, K. and Arstorp, A-T. (2017), Professional digital competence framework for teachers.

Laurillard, D. (2016). The educational problem that MOOCs could solve: professional development for teachers of disadvantaged students. Research in Learning Technology, 24(1), 29369.

Lawrence, J.E. and Tar, U.A. (2018): Factors that influence teachers' adoption and integration of ICT in teaching/learning process, Educational Media International,

Merchie, E., Tuytens, M., Devos, G. and Vanderlinde, R. (2018) Evaluating teachers' professional development initiatives: towards an extended evaluative framework, Research Papers in Education, 33:2, 143-168.

NMC Horizon report (2017), 2017 Higher Education Edition, available online at https://www.nmc.org/publication/nmc-horizon-report-2017-highereducation-edition/, last accessed $20^{\text {th }}$ March 2018.

OUA (2018), Open Universities Australia Higher Education Marketing 
Opportunities Overview, Edition 2, Melbourne: Open Universities Australia. Patton, M. Q. (2008). Utilization focused evaluation. Saint Paul, MN: Sage.

Scott, C.L. (2015a), The futures of learning 1: why must learning content and methods change in the $21^{\text {st }}$ Century? Education, research and foresight working papers, available online at http://unesdoc.unesco.org/images/0023/002348/234807E.pdf, last accessed $26^{\text {th }}$ March 2018.

Scott, C.L. (2015b), The futures of learning 2: what kinds of learning for the $21^{\text {st }}$ Century? Education, research and foresight working papers, available online at http://unesdoc.unesco.org/images/0024/002429/242996e.pdf, last accessed $26^{\text {th }}$ March 2018.

Scott, C.L. (2015)c, The futures of learning 3: what kinds of pedagogies for the $21^{\text {st }}$ Century? Education, research and foresight working papers, available online at http://unesdoc.unesco.org/images/0024/002431/243126e.pdf, last accessed $26^{\text {th }}$ March 2018.

Teaching and Learning National Forum for the enhancement of teaching and learning in Higher Education (2015), Mapping CPD pathways

Thomson, K.E. and Trigwell, K.R. (2016): The role of informal conversations in developing university teaching?, Studies in Higher Education

Tondeur, J., can Brank, J. and Ertmer, P.A. (2016), Understanding the relationship between teachers' pedagogical beliefs and technology use in education: a systematic review of qualitative evidence, Education Tech Research Dev, 65: 555-575.

van Lankveld, T., Schoonenboom, J., Volman, M., Croiset, G, and Beishuizen, J. (2017) Developing a teacher identity in the university context: a systematic review of the literature, Higher Education Research and Development, 36:2, 325-342,

Wenner, J.A. and Campbell, T., (2017), The theoretical and empirical basis of teacher leadership: a review of the literature, Review of educational research, Vol. 87, No. 1, 134-171.

Witthaus, G., Inamorato dos Santos, Childs, M., Tannhauser, A-C., Conole, G., Nkuyubwatsi, Punie, Y., (2016), Validation of non-formal MOOC-based learning: an analysis of assessment and recognition practices in Europe (OpenCred), a JRC Science for policy report, available online at http://publications.jrc.ec.europa.eu/repository/bitstream/JRC96968/lfna2766 0enn.pdf, last accessed $20^{\text {th }}$ March 2018.

World Economic Forum (2016), The future of jobs and skills, available online at http://reports.weforum.org/future-of-jobs-2016/chapter-1-the-future-ofjobs-and-skills/, last accessed $21^{\text {st }}$ March 2018. 